\title{
Flexible mental processes in numerical size judgments: The case of Hebrew letters that are used to convey numbers
}

\author{
IRENE RAZPURKER-APFELD and ASHER KORIAT \\ University of Haifa, Haifa, Israel
}

\begin{abstract}
In addition to its primary linguistic function, the Hebrew alphabet is sometimes used as a means of number notation (i.e., the system of gematria). Hebrew letters, Arabic numerals, Hebrew number names, and Hebrew letter names were used in a numerical size comparison task, in which two visually presented symbols were compared for numerical value while irrelevant variations in their physical size had to be ignored. A size congruity effect, indicated by faster responses when differences in physical and numerical size were consistent, was larger for Arabic numerals than for number names. The effect for Hebrew letters was similar to that for Arabic numerals and was stronger than that observed for letter names. These results suggest flexible processing of Hebrew letters, so that they function as ideographic symbols in an arithmetic context. A distance effect, indicated by an inverse relationship between reaction time and numerical distance, was found for all notations but was particularly strong for Hebrew letters.
\end{abstract}

Numbers can be expressed in several distinct notations. Previous studies have suggested that these various visual formats are processed differently (Besner \& Coltheart, 1979; Dehaene, Bossini, \& Giraux, 1993; Fias, Reynvoet, \& Brysbaert, 2001; Foltz, Poltrock, \& Potts, 1984; Ischebeck, 2003; Ito \& Hatta, 2003; Takahashi \& Green, 1983; Vaid, 1985). The present study explores further the processing pathways originating from different number notations by taking advantage of a unique number notation system that exists in Hebrew, which can provide further insights into the processes underlying numerical cognition and visual word recognition.

Research on visual word recognition has given rise to a dual-route model in which words can be read using a phonologically mediated route or a direct route. The phonologically mediated route involves the application of grapheme-to-phoneme correspondence rules to derive a phonological representation, which is then used to access the lexicon. In the direct route, on the other hand, lexical meaning is retrieved directly from the orthographic representation (see Coltheart, Curtis, Atkins, \& Haller, 1993).

This dual-route approach has been extended to the study of numerical cognition. It has been proposed that Arabic numerals (e.g., 5) reflect an ideographic representation in which the visual symbol has an arbitrary correspondence

This research was conducted at the Institute of Information Processing and Decision Making, University of Haifa. We thank Arthur M. Glenberg, Arthur B. Markman, Jeffrey N. Rouder, Jyotsna Vaid, William P. Banks, and two anonymous reviewers for providing useful comments on earlier versions of the manuscript. Correspondence concerning this article should be addressed to I. Razpurker-Apfeld, Institute of Information Processing and Decision Making, University of Haifa, Haifa 31905 , Israel (e-mail: irenea@013.net.il). to the number concept as well as to its phonological representation. Therefore, they are processed by the direct, lexical route. Number names (e.g., five), in contrast, use an alphabetic representation in which the written symbols stand for the spoken units of the word, and hence may be processed via the phonologically mediated route (Besner \& Coltheart, 1979; Fias et al., 2001). The processing of these two number notation systems has been most commonly investigated using a numerical size comparison task in which participants decide which of two visually presented digits is numerically larger while they ignore irrelevant variations in the digits' physical size. We focus on two classic effects: the size congruity effect, indicated by shorter reaction times (RTs) when numerical and physical sizes are congruent rather than incongruent, and the distance effect, indicated by an inverse relationship between RT and the numerical distance between two numbers (e.g., comparing 2 and 8 is faster than comparing 2 and 3 ).

The size congruity effect has been consistently observed for the ideographic, Arabic numerals (Besner \& Coltheart, 1979; Foltz et al., 1984; Henik \& Tzelgov, 1982; Ito \& Hatta, 2003; Vaid, 1985), but it has not always been found for number names (Besner \& Coltheart, 1979; Vaid, 1985). Moreover, the differences between number formats were extended to the Japanese writing system, where the ideographic kanji script yielded a pattern similar to the one found for Arabic numerals, and the nonideographic kana script was processed similarly to English number names (Takahashi \& Green, 1983; see also Ito \& Hatta, 2003). However, Vaid demonstrated size congruity effects of similar magnitude for Arabic numerals and for alphabetic English number names. Nevertheless, she also found that when numbers were written in a syllabic script (Hindi), in which the visual symbols correspond to the 
spoken syllables, numerical judgments were unaffected by differences in physical size.

The general conclusion from these findings is that when a script enables print-to-sound mapping, the Stroop-like congruity effect diminishes or disappears because of reliance on the phonological route, which is less susceptible to variations in physical-visual parameters. In contrast, the size congruity effect for ideographic numbers derives from mechanisms that depend on the visual form of the stimulus (Besner \& Coltheart, 1979; Vaid, 1985).

Several theorists have suggested that the direct route is used for reading frequent words, so that phonological information contributes to the activation of word meaning only for low-frequency words (Grainger \& Jacobs, 1996). Thus, perhaps Arabic numerals are read by the direct route because of their high frequency. However, number names are also quite common words, so why do they not always yield a size congruity effect that implies direct processing? According to the time-course-based dual-route theory (Jared \& Seidenberg, 1991; Seidenberg, 1985), it is possible that in a numerical judgment task, the number names are not processed fast enough to enable direct access to meaning and consequently demonstrate weak congruity effects.

Unlike the congruity effect, the distance effect has been observed for ideographic as well as for nonideographic number notations (Besner \& Coltheart, 1979; Dehaene \& Akhavein, 1995; Henik \& Tzelgov, 1982; Holender \& Peereman, 1987; Moyer \& Landauer, 1967). The distance effect has been taken to support the notion that numbers in general are represented on a mental "number line" continuum that embodies number magnitude. Such a representation preserves the numerical size relationships and enables perceptual-like comparative judgments (Dehaene, 1989; Moyer, 1973; Restle, 1970).

In the present study, we sought to gain further insight into the differences among numerical representations by capitalizing on a unique category of number notation that exists in Hebrew, which shares some features with Arabic numbers but other features with number names. The Hebrew writing system is an alphabetic system (see Frost \& Bentin, 1992): It has 22 letters that are used as in English to form words. In addition to their primary linguistic function, however, Hebrew letters also have a counting role within the notation system referred to as gematria: They serve as numbers in many contexts, such as in the Hebrew calendar, in the Bible, in numbering book chapters, in numbering the pages of religious books, and with the days of the week (e.g., Monday is interchangeably Yom Sheni or Yom Beth, "second day"). It should be stressed, however, that numbers are normally represented by Arabic numerals, as in English.

In the Hebrew gematric system, each letter has a numerical value according to its ordinal position in the alphabet, but the function relating letters to numbers is complex: The first ten letters stand for the numbers 1-10. For example, aleph ( $(\boldsymbol{\aleph})$ stands for 1, beth (ב) for 2, and so on. The next eight letters have values of tens (between 20 and 90), and the remaining four letters have values of hundreds (100-400). For example, the letter kaph (כ) stands for 20, the letter lamed (ל) stands for 30, and the letter resh (ר) stands for 200. A string such as lamed-beth (לב) represents the number 32, but it is also a word, designating heart.

We used the numerical size comparison task to examine the size congruity and distance effects in four notation systems: Arabic numerals (e.g., 3), Hebrew number names (שלוש, meaning three), gematric letters $(\lambda$, the third Hebrew letter, standing for 3), and Hebrew letter names (גימל, the name of the third letter). ${ }^{1}$ The alphabetic number and letter names were written according to the direction of writing in Hebrew, from right to left. The frequency and speed of processing of these number notations were also considered, because they may moderate the use of the direct versus the phonological route. Whereas Arabic numerals are presumably the most common notation, the gematric Hebrew letter notation is not common (McCauley, 2002). ${ }^{2}$

The question of most interest was whether Hebrew letters demonstrate processing flexibility by acting like ideographic numbers in their gematric function (as with $\mathrm{B}$, designating 5) and like nonideographic numbers when they stand for their names (as with האי, indicating the name of the fifth letter). On the one hand, assuming that low frequency of usage contributes to reliance on the phonological route, gematric Hebrew letters should yield a weak size congruity effect, perhaps like the Hebrew letter names, which are the least frequent form of notation (McCauley, 2002). ${ }^{3}$ On the other hand, because the visual symbol has an arbitrary correspondence to the number concept in the case of gematric Hebrew letters, these letters might be expected to yield a strong size congruity effect, like that elicited by Arabic numerals. In addition, we were also interested to see whether the distance effect, which has been observed so far for all number notations, will be found for gematric Hebrew letters and Hebrew letter names, which have not been examined before.

\section{METHOD}

\section{Participants}

Sixteen students at the University of Haifa (12 women and 4 men, ages 20-24) participated in the experiment. All were native Hebrew speakers who had normal or corrected-to-normal vision.

\section{Stimuli and Apparatus}

The experiment was conducted on a Silicon Graphics workstation. The stimuli appeared in white against a gray background and were viewed from a distance of $80 \mathrm{~cm}$.

For each notation system (Arabic numerals, Hebrew number names, gematric Hebrew letters, Hebrew letter names), each of the numbers 1-9 was paired with all of the other numbers, to create 36 pairs in a repeated-set design (Foltz et al., 1984). ${ }^{4}$ The two numbers appeared side by side at the center of the screen. Either number in a pair could appear physically large or small and could appear on the left or the right side. The distance between the numbers in a pair was $1.8^{\circ}$ of visual angle. When a number appeared physically small, it subtended $0.4^{\circ}$ in height $(6 \mathrm{~mm})$. Physically large numbers were twice as large as the small ones. The width of the stimuli varied according to the notation system: $0.4^{\circ}$ for Arabic numerals and gematric letters, $0.7^{\circ}-1.8^{\circ}$ for Hebrew number names, and $0.4^{\circ}-1.2^{\circ}$ for Hebrew letter names. In the congruent condition, the numerically 
larger number was also larger physically, whereas the reverse was true for the incongruent condition. Each number and each physical size appeared on the left and the right side equally often. Figure 1 presents an example of a specific pair in the congruent and incongruent conditions for the four number notations. All combinations of physical size and position were repeated twice for each pair, yielding 288 critical trials.

Single-letter Hebrew stimuli can be compared by referring to their ordinal position in the alphabet. This is also true for the Hebrew letter names, which always begin with the letter they designate (e.g., beth, gimel, and daleth stand for $b, g$, and $d$, respectively). To induce participants to rely on an arithmetic mode of comparison, filler trials were included in all notation blocks. These trials consisted of 92 pairs of two-digit numbers, mixed with the other trials. Thus, altogether, an experimental block included 380 trials

\section{Design}

Number notation (four notations), congruity (congruent vs. incongruent), and numerical distance (1-8, for the critical trials) were manipulated within participants. Notation was blocked, but within each block all combinations of the other two factors appeared in a random order. The experiment began with a 100 -trial practice block in which 2 two-digit numbers from different notation systems appeared in different physical sizes in each trial. This block was followed by four experimental blocks whose order was determined according to a Latin square design.

\section{Procedure}

Prior to each block, participants were informed about the notation they were about to receive, and before the gematric letter and Hebrew letter name blocks they were reminded that the letters have a numerical value. Each trial began with a 50 -msec fixation cross at the center of the screen. This was followed by a pair of numbers, which appeared centrally for $10 \mathrm{sec}$ or until a response was made. Participants had to decide as rapidly and accurately as possible which of the two numbers was numerically larger by pressing a key corresponding to the spatial position of the larger number. RT was measured from the onset of numbers, and the intertrial interval was $1,000 \mathrm{msec}$.

\section{RESULTS}

All RT analyses are based on participants' mean RTs for correct responses in the critical trials. RTs outside the range $250-2,500 \mathrm{msec}$ were omitted from the analyses $(1 \%$ of all trials). Error rate was low (overall mean of $2.7 \%$ ), and there was no indication of a speed-accuracy trade-off. Therefore, error rate data are not discussed further.

Because the number of observations for the numerical distance of 8 (seven to eight per participant) was much smaller than for the other distances, this numerical distance was not included in the analyses to be reported.

\section{The Congruity Effect}

As an index of the magnitude of the congruity effect for each participant and notation, we used the mean RTs of the incongruent condition minus the mean RTs of the congruent one. Figure 2 depicts mean differences across participants, with higher positive means indicating stronger congruity effects. A one-way ANOVA for repeated observations performed on these differences yielded a significant effect of notation $[F(3,45)=10.58, p<.0001$, $\left.\eta_{\mathrm{p}}^{2}=.41\right]$. A post hoc Tukey HSD analysis revealed that the effect sizes for Arabic numerals and gematric letters did not differ, but they were both significantly different from the effect size for Hebrew letter names $(p<.05)$. Figure 2 shows intermediate effect sizes for the gematric letters (between Arabic numerals and Hebrew number names) and for the Hebrew number names (between gematric letters and Hebrew letter names).

\section{The Numerical Distance Effect}

Mean RTs for each notation system are plotted in Figure 3 as a function of numerical distance. A repeated notation $\times$ numerical distance ANOVA on RTs yielded a main effect of notation $\left[F(3,45)=54.38, p<.0001, \eta_{\mathrm{p}}^{2}=.78\right]$. A post hoc Tukey analysis revealed that RTs for Arabic numerals were significantly shorter than those for gematric letters, which in turn were significantly shorter than those for Hebrew number and letter names $(p<.05)$. The effect of numerical distance was significant $[F(6,90)=$ $\left.50.60, p<.0001, \eta_{\mathrm{p}}^{2}=.77\right]$, and so was its interaction with notation $\left[F(18,270)=1.95, p<.02, \eta_{\mathrm{p}}^{2}=.12\right]$. The effect of distance was significant for each notation: Arabic numerals $\left[F(6,90)=26.71, p<.0001, \eta_{\mathrm{p}}^{2}=.64\right]$, gematric letters $\left[F(6,90)=28.05, p<.0001, \eta_{\mathrm{p}}^{2}=.65\right]$, Hebrew number names $\left[F(6,90)=8.45, p<.0001, \eta_{\mathrm{p}}^{2}=.36\right]$, and Hebrew letter names $\left[F(6,90)=9.64, p<.0001, \eta_{\mathrm{p}}^{2}=\right.$ .39].

Slopes of best-fitting linear functions relating RT to numerical distance were calculated separately for each participant and each notation. These slopes were indexed by standardized regression coefficients, equivalent to the appropriate simple correlation coefficients. Results of $t$-test analyses confirmed that the correlation deviated signifi-

\begin{tabular}{|c|c|c|c|c|}
\hline Congruity & $\begin{array}{c}\text { Arabic } \\
\text { Numerals }\end{array}$ & $\begin{array}{c}\text { Hebrew } \\
\text { Number Names }\end{array}$ & $\begin{array}{c}\text { Gematric } \\
\text { Hebrew } \\
\text { Letters }\end{array}$ & $\begin{array}{c}\text { Hebrew } \\
\text { Letter Names }\end{array}$ \\
\hline Congruent & 5 & חמש & ה & הא \\
\hline Incongruent & 2 & שתיים & ב & בית \\
\hline
\end{tabular}

Figure 1. Example of the congruent and incongruent conditions, using a comparison of 2 and 5 in each of the four notation systems. 


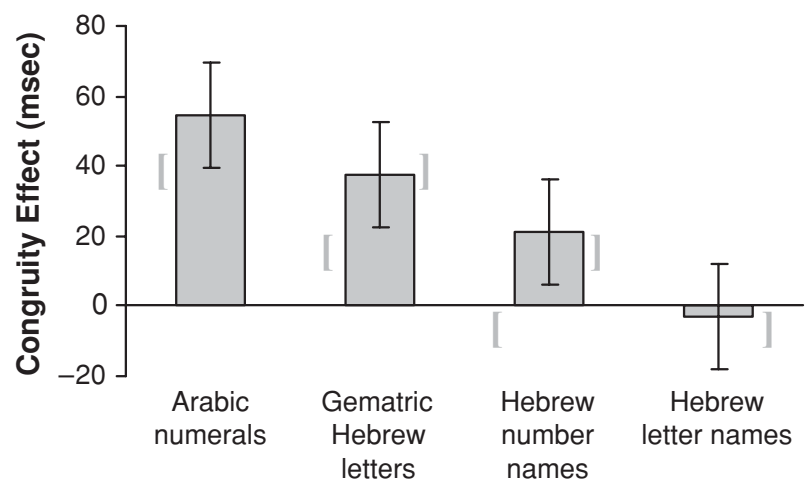

Notation

Figure 2. The size congruity effect for each of the four notation systems. The effect is represented by positive values of the mean difference in RTs (incongruent-congruent). Error bars at each notation represent within-participants $95 \%$ confidence intervals (Loftus \& Masson, 1994) based on the appropriate error term of the notation effect. Brackets across the bars indicate adjacent pairs of means that are not significantly different, according to Tukey HSD tests.

cantly from zero for each notation: Arabic numerals $[r=$ $-.53 ; t(15)=13.53, p<.0001]$, gematric letters $[r=$ $-.65 ; t(15)=14.42, p<.0001]$, Hebrew number names $[r=-.47 ; t(15)=7.13, p<.0001]$, and Hebrew letter names $[r=-.50 ; t(15)=6.3, p<.0001]$.

These findings confirm the presence of a distance effect for each notation system, but they also suggest that this effect might be particularly strong for the gematric letters. Planned comparisons were performed to compare the RT-distance correlation for gematric letters to those for the other notations. The correlation for gematric letters was significantly higher than those for Arabic numerals $[t(15)=2.3, p<.04]$ and Hebrew number names $[t(15)=$ $2.72, p<.02]$, and was almost significantly higher than that for Hebrew letter names $[t(15)=1.89, p<.08]$. Thus, although the distance effect was found for all four notations, it was most pronounced for gematric letters.
A notation $\times$ distance $\times$ congruity ANOVA yielded $F<1$ for the interaction between numerical distance and congruity, as well as for the triple interaction. These results indicate that the presence or absence of the size congruity effect did not vary as a function of numerical distance. The distance effect was significant for both the congruent and incongruent conditions with each notation $(p<.01)$.

\section{DISCUSSION}

In this study, we examined the size congruity effect and the distance effect in a numerical-size comparative judgment task for four numerical notations. Consistent with the literature, the congruity effect for Hebrew number names was weaker than that found for Arabic numerals. Hebrew letters were of special interest because they represent a unique notation system: On the one hand, they are alphabetic in nature, consisting of the same orthographic units used in reading. On the other hand, each letter also has a numerical value according to gematria, so the letters may function as ideographic symbols as well. The results indicated that gematric Hebrew letters yielded a congruity effect similar to the one found for ideographic Arabic numerals, and critically different from the effect for Hebrew letter names, which was absent.

These findings demonstrate the flexibility of the number processing system, at least where single-digit numbers are concerned: Hebrew letters seem to be processed through a direct visual route when they stand directly for numbers but are processed phonologically when they represent the name of the letter. In the former case, the coding directly maps the visual symbol to its numerical meaning, possibly without mediation of the phonological route. This occurs despite the gematric Hebrew letters having a phonological match. For the letter names, in contrast, the Hebrew words that activate the names of letters are processed via the indirect, phonological route, and thus fail to yield a size congruity effect (Besner \& Coltheart, 1979; Vaid, 1985). This pattern of results indicates that Hebrew

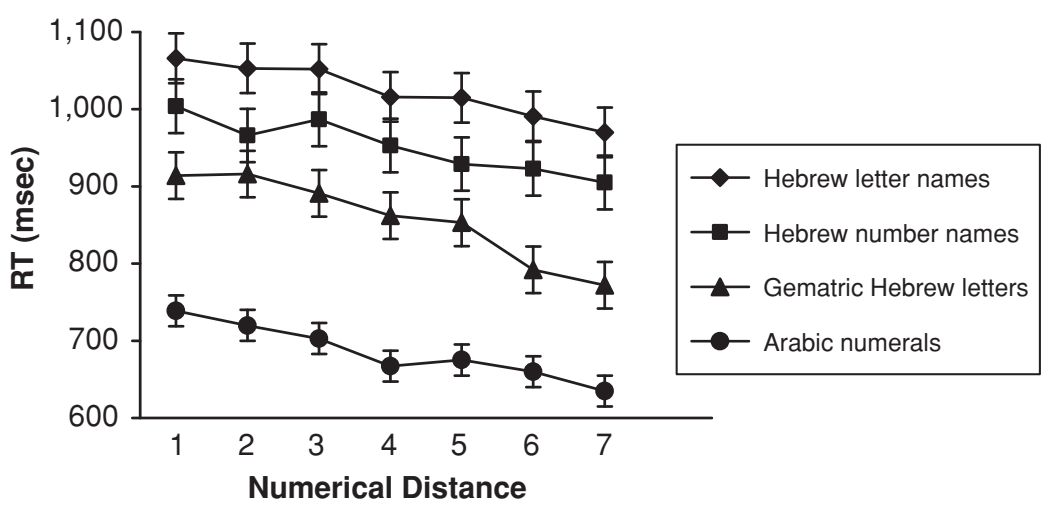

Figure 3. Mean RTs as a function of numerical distance for each of the four notation systems. Error bars for each notation represent within-participants $95 \%$ confidence intervals based on the appropriate error terms of the distance simple effects. 
letters can function as ideographs and can activate a direct processing route under the appropriate task conditions.

The results appear consistent with the time-coursebased dual-route theory (Jared \& Seidenberg, 1991; Seidenberg, 1985), according to which the contribution of phonological information to the activation of meaning depends on the time course of recognition: With a slower time course, there is more opportunity for the phonological route to be activated. Indeed, the magnitude of the congruity effect increased the faster a notation was processed. Thus, the Arabic numerals, with the fastest mean RTs (possibly because of their high frequency) yielded the strongest congruity effect, whereas the less common Hebrew letter names both yielded the slowest RTs and failed to yield any congruity effect. Consistent with the theory, gematric Hebrew letters, which were processed relatively fast and showed a rather strong congruity effect, were most likely processed via the direct route. Gematric letters represent an exceptional case in which less commonly used stimuli yield fast processing. Hebrew number names are also exceptional in the present context because in spite of their high frequency, they were processed quite slowly. This may account for the intermediate congruity effect they yielded, possibly reflecting processing that combines the direct and the phonological routes. Thus, the required processing time may moderate the use of the reading route.

Conversely, one could argue that the gematric letters may have been processed by a phonological route, but still showed a congruity effect simply because of their fast processing. However, although the phonological route was likely activated by Hebrew letter names, a congruity effect for those stimuli was not consistently observed for the relatively fast processing associated with large numerical distances. Indeed, there was no interaction between congruity and distance with that notation system. Thus, the congruity effect is more readily explained by a directroute account.

Our results are also in line with neuropsychological evidence suggesting that different mechanisms underlie the processing of different number notations. In the phenomenon known as number sparing, which is typically observed in patients suffering from alexia, alphabetic reading is impaired, whereas the reading of ideographic numbers is almost intact. Cohen, Dehaene, Chochon, Lehéricy, and Naccache (2000) reported a patient with a lesion in her left perisylvian area who exhibited a selective preservation of numbers represented as Arabic numerals. She could not read or respond to questions of numerical knowledge when presented with numbers in a verbal format, but when numbers were represented in an Arabic format or as quantities, she performed number comparison tasks rather well. Other such cases, and a similar distinction between the processing of kana and kanji for Japanese patients, have been reported by others (Albert, Yamadori, Gardner, \& Howes, 1973; Cohen \& Dehaene, 2000; Yamadori, 1975). Given that Hebrew letters function sometimes as alphabetic units and sometimes as numerals, perhaps Hebrew-alexic patients who cannot read in a linguistic context might be able to access the numerical values of the very same stimuli in an arithmetic context.

As expected, a distance effect was found for all four notation systems. The finding of a distance effect even for the Hebrew letter names, which have a very rare orthographic usage and do not elicit a congruity effect, suggests that these letter names are translated into an abstract commonmagnitude representation, and thus also function like numbers (Dehaene, 1992; McCloskey, 1992). Surprisingly, however, the distance effect was stronger for the gematric Hebrew letter notation than for the other notations. This enhanced effect might derive from an added effect of the letters' ordinal positions in the alphabet. Thus, Hebrew letters may be activated not only by the common numerical representation that was assumed by both McCloskey and Dehaene, but also by a representation based on letter position in the alphabet.

To summarize, the present study showed notation-specific size congruity effects, along with a distance effect common to all notations. Gematric Hebrew letters yielded a size congruity effect similar in magnitude to that found for Arabic numbers and for Hebrew number names, but unlike that for Hebrew letter names. This suggests that when letters have a counting role, they may act as ideographs, but when they form alphabetic words, phonological information is activated based on such factors as word frequency and the time course of processing. The dual status of Hebrew letters should be further examined by comparing their processing in a numerical versus a linguistic context.

\section{REFERENCES}

Albert, M. L., Yamadori, A., Gardner, H., \& Howes, D. (1973). Comprehension in alexia. Brain, 96, 317-328.

Besner, D., \& Coltheart, M. (1979). Ideographic and alphabetic processing in skilled reading of English. Neuropsychologia, 17, $467-$ 472 .

Cohen, L., \& Dehaene, S. (2000). Calculating without reading: Unsuspected residual abilities in pure alexia. Cognitive Neuropsychology, 17, 563-583.

Cohen, L., Dehaene, S., Chochon, F., Lehéricy, S., \& Naccache, L. (2000). Language and calculation within the parietal lobe: A combined cognitive, anatomical and fMRI study. Neuropsychologia, 38, 1426-1440

Coltheart, M., Curtis, B., Atkins, P., \& Haller, M. (1993). Models of reading aloud: Dual-route and parallel-distributed-processing approaches. Psychological Review, 100, 589-608.

Dehaene, S. (1989). The psychophysics of numerical comparison: A reexamination of apparently incompatible data. Perception \& Psychophysics, 45, 557-566.

Dehaene, S. (1992). Varieties of numerical abilities. Cognition, 44, 1-42.

Dehaene, S., \& Akhavein, R. (1995). Attention, automaticity, and levels of representation in number processing. Journal of Experimental Psychology: Learning, Memory, \& Cognition, 21, 314-326.

Dehaene, S., Bossini, S., \& Giraux, P. (1993). The mental representation of parity and number magnitude. Journal of Experimental Psychology: General, 122, 371-396.

Fias, W., Reynvoet, B., \& Brysbaert, M. (2001). Are Arabic numerals processed as pictures in a Stroop interference task? Psychological Research, 65, 242-249.

Foltz, G. S., Poltrock, S. E., \& Potts, G. R. (1984). Mental comparison of size and magnitude: Size congruity effects. Journal of Experimental Psychology: Learning, Memory, \& Cognition, 10, 442-453.

Frost, R., \& BENTIN, S. (1992). Reading consonants and guessing vowels: 
Visual word recognition in Hebrew orthography. In R. Frost \& L. Katz (Eds.), Advances in psychology: Vol. 94. Orthography, phonology, morphology, and meaning (pp. 27-44). Amsterdam: North-Holland.

Grainger, J., \& JACOBS, A. M. (1996). Orthographic processing in visual word recognition: A multiple read-out model. Psychological Review, 103, 518-565.

HeNIK, A., \& Tzelgov, J. (1982). Is three greater than five: The relation between physical and semantic size in comparison tasks. Memory \& Cognition, 10, 389-395.

Holender, D., \& Peereman, R. (1987). Differential processing of phonographic and logographic single-digit numbers by the two hemispheres. In G. Deloche \& X. Seron (Eds.), Mathematical disabilities: A cognitive neuropsychological perspective (pp. 43-85). Hillsdale, NJ: Erlbaum.

IscheBECK, A. (2003). Differences between digit naming and number word reading in a flanker task. Memory \& Cognition, 31, 529-537.

Iтo, Y., \& HatTa, T. (2003). Semantic processing of Arabic, Kanji, and Kana numbers: Evidence from interference in physical and numerical size judgments. Memory \& Cognition, 31, 360-368.

JARED, D., \& SEIDEnberg, M. S. (1991). Does word identification proceed from spelling to sound to meaning? Journal of Experimental Psychology: General, 120, 358-394.

Koriat, A. (1984). Reading without vowels: Lexical access in Hebrew. In H. Bouma \& D. G. Bouwhuis (Eds.), Attention and performance X: Control of language processes (pp. 227-242). Hillsdale, NJ: Erlbaum.

Loftus, G. R., \& Masson, M. E. J. (1994). Using confidence intervals in within-subject designs. Psychonomic Bulletin \& Review, 1, 476490.

McCauley, A. (2002). A Web-based Hebrew word frequency database. Accessed May 10, 2005, at homepages.inf.ed.ac.uk/s9623281/.

MCCloskey, M. (1992). Cognitive mechanisms in numerical processing: Evidence from acquired dyscalculia. Cognition, 44, 107-157.

Moyer, R. S. (1973). Comparing objects in memory: Evidence suggesting an internal psychophysics. Perception \& Psychophysics, 13, 180-184.

Moyer, R. S., \& Landauer, T. K. (1967). Time required for judgements of numerical inequality. Nature, 215, 1519-1520.
Restle, F. (1970). Speed of adding and comparing numbers. Journal of Experimental Psychology, 83, 274-278.

Seidenberg, M. S. (1985). The time course of phonological code activation in two writing systems. Cognition, 19, 1-30.

Takahashi, A., \& Green, D. W. (1983). Numerical judgments with Kanji and Kana. Neuropsychologia, 21, 259-263.

VAID, J. (1985). Numerical size comparisons in a phonologically transparent script. Perception \& Psychophysics, 37, 592-595.

YAMADORI, A. (1975). Ideogram reading in alexia. Brain, 98, 231-238.

\section{NOTES}

1. The names of letters in Hebrew have conventional spellings: בא (pronounced "aleph") for the first letter, בית (pronounced "bet") for the second letter, and so on.

2. In Hebrew, there are no single-letter words (like $a$ in English), so when a single letter appears in text, it typically appears in its counting role (gematria).

3. An exception is two-letter names that are of high frequency because they are homographs. In unpointed Hebrew (see Koriat, 1984), the same word may have different pronunciations, and hence different meanings. Thus, בית is the name of the second letter, but it can also have a different pronunciation signifying "house."

4. In a repeated-set design, each item is paired equally often with every other item in a given set, and the pairs are presented repeatedly. In a fixed-pairs design, each item is paired with only a few other items from the set, and the chosen pairs are presented repeatedly. The former design, in contrast with the latter, plays a role in reducing the chance of responding by remembering previous responses to identical trials. Although in this design each numerical distance does not occur equally often, the number of appearances of a specific pair is exactly the same. Thus, since distance is derived from processing a particular pair, the correlation between numerical distance and pair variability should not weaken our claims concerning numerical distance.

(Manuscript received February 25, 2005; revision accepted for publication June 14, 2005.) 